Oil \& Gas Science and Technology - Rev. IFP, Vol. 54 (1999), No. 4, pp. 525-536

Copyright (C) 1999, Éditions Technip

\title{
Structural Modification of Cobalt Catalysts: Effect of Wetting Studied by X-Ray and Infrared Techniques
}

\author{
A. Khodakov' ', O. Ducreux², J. Lynch², B. Rebours² and P. Chaumette ${ }^{2}$ \\ 115200 Park Row, Houson TX 77084 - United States \\ 2 Institut français du pétrole, 1 et 4, avenue de Bois-Préau, 92852 Rueil-Malmaison Cedex - France \\ e-mail: john.lynch@ifp.fr
}

\begin{abstract}
Résumé - Modifications structurales de catalyseurs à base de cobalt : étude par rayons $\mathrm{X}$ et infrarouges de l'effet de mouillage par l'eau — L'effet de mouillage par l'eau sur la structure et sur la localisation des formes de cobalt sur différents supports $\left(\mathrm{Al}_{2} \mathrm{O}_{3}, \mathrm{SiO}_{2}, \mathrm{TiO}_{2}, \mathrm{HZSM}-5\right.$ zéolithe) a été étudié par diffraction des rayons $\mathrm{X}$, spectroscopie infrarouge à transformée de Fourier de $\mathrm{CO}$ adsorbé, spectroscopie de photoélectrons $\mathrm{X}$ et analyse de la structure fine de seuils d'absorption X.

Pour des catalyseurs à base de cobalt préalablement réduits et passivés, le mouillage par l'eau, même en l'absence d'élément promoteur, résulte en une réduction substantielle de la concentration de phases cristallines contenant du cobalt ainsi qu'en une modification des sites de surface. La diminution de la concentration en $\mathrm{Co}_{3} \mathrm{O}_{4}$ sous forme cristallisée est particulièrement importante sur des catalyseurs préparés par imprégnation de cobalt sur la silice et sur un mélange de $\mathrm{Co}_{3} \mathrm{O}_{4}$ et de zéolithe HZSM-5. La saturation en eau d'un échantillon $\mathrm{Co} / \mathrm{SiO}_{2}$ passivé conduit à un solide amorphe dont la structure locale s'apparente à $\mathrm{Co}_{2} \mathrm{SiO}_{4}$. Pour les catalyseurs $\mathrm{Co} / \mathrm{Al}_{2} \mathrm{O}_{3}$ and $\mathrm{Co} / \mathrm{TiO}_{2}$, l'effet du mouillage sur la concentration de $\mathrm{Co}_{3} \mathrm{O}_{4}$ sous forme cristallisée est relativement faible.

Mots-clés : Fischer-Tropsch, cobalt, eau, redispersion, silicate.
\end{abstract}

Abstract - Structural Modification of Cobalt Catalysts: Effect of Wetting Studied by X-Ray and Infrared Techniques - The effect of wetting on the structure and localisation of cobalt species on various supports $\left(\mathrm{Al}_{2} \mathrm{O}_{3}, \mathrm{SiO}_{2}, \mathrm{TiO}_{2}, \mathrm{HZSM}\right.$-5 zeolite) was studied using X-ray diffraction, Fourier transform infrared spectroscopy with $\mathrm{CO}$ as a molecular probe, X-ray photoelectron spectroscopy and extended $X$-ray absorption fine structure analysis.

Aqueous impregnation to incipient wetness of reduced and passivated cobalt catalysts results, even in the absence of any promoter, in a considerable decrease in the concentration of Co crystalline phases and modifies the surface sites. The decrease in the concentration of $\mathrm{Co}_{3} \mathrm{O}_{4}$ crystallites was especially pronounced on silica supported catalysts prepared via impregnation of cobalt and on a mixture of $\mathrm{Co}_{3} \mathrm{O}_{4}$ and HZSM-5 zeolite. Saturation with water of the passivated $\mathrm{Co} / \mathrm{SiO}{ }_{2}$ sample results in an amorphous solid with a local structure close to that of $\mathrm{Co}_{2} \mathrm{SiO}_{4}$. For $\mathrm{Co} / \mathrm{Al}_{2} \mathrm{O}_{3}$ and $\mathrm{Co} / \mathrm{TiO} \mathrm{O}_{2}$ catalysts, the effect of wetting on the concentration of $\mathrm{Co}_{3} \mathrm{O}_{4}$ crystalline phase was considerably smaller.

Keywords: Fischer-Tropsch, cobalt, water, redispersion, silicate. 


\section{INTRODUCTION}

Co catalysts are effective in the Fischer Tropsch synthesis, nitrogen oxide removal from exhaust gases and other catalytic processes [1-4]. Activity and selectivity of these catalysts depend on the nature of supported Co species. It is usually suggested that activity of these cobalt catalysts can be enhanced by introducing an additional component, a "promoter", using impregnation or some other technique. In many catalytic studies it is suggested that this promoter modifies the nature, dispersion, localisation and electronic properties of Co species, and that it could create new active sites resulting in modification of the activity of the catalysts. However, little information is available on how the impregnation procedure itself could change the localisation and electronic properties of the Co species on different supports.

Modification of Co with promoters added by a secondary impregnation is a common technique employed for preparation of promoted catalysts [5]. Haddad and Goodwin [6] have found that impregnation with distilled water followed by drying had a significant effect on the structure of reduced and passivated $\mathrm{Co} / \mathrm{SiO}_{2}$ catalysts. The $\mathrm{Co}$ oxide phase declined in favour of an amorphous Co silicate/hydrosilicate phase which can be reduced under hydrogen only at $1070 \mathrm{~K}$. In addition, since water is produced as a by product of the Fischer Tropsch synthesis, knowledge of the effect of water on the metallic phase in supported cobalt based catalysts may be important in understanding the evolution of the active phase during reaction.

It can be suggested that the aqueous impregnation of Co supported catalysts could affect the structure and localisation of Co species to a different extent on different supports. In this paper we study the effect of wetting with distilled water on the structure of metallic cobalt on common catalytic supports $\left(\mathrm{Al}_{2} \mathrm{O}_{3}, \mathrm{TiO}_{2}, \mathrm{HZSM}-5\right.$ zeolite, $\left.\mathrm{SiO}_{2}\right)$ using X-ray diffraction (XRD), X-ray photoelectron spectroscopy (XPS), extended X-ray absorption fine structure (EXAFS) and Fourier transform infrared spectroscopy (FTIR) with carbon monoxide as a molecular probe.

\section{EXPERIMENTAL}

\subsection{Catalyst Preparation}

Bulk $\mathrm{Co}_{3} \mathrm{O}_{4}$ purchased from Ultrex was used as a control sample. Mechanical mixtures of bulk $\mathrm{Co}_{3} \mathrm{O}_{4}$ and silica or HZSM-5 zeolite with $\mathrm{Si} / \mathrm{Al}$ ratio of 18 were also studied. Three samples were prepared via impregnation using a cobalt nitrate solution on alumina, titanium oxide (Degussa P25) and silica. A second silica supported sample was synthesised using the sol-gel technique [7] and will be referred to here as $\mathrm{Co} / \mathrm{SiO}_{2}$ (sol). Prior to analysis, the catalysts were calcined under air at $873 \mathrm{~K}$ for $5 \mathrm{~h}$. The Co content was measured by $\mathrm{X}$-ray fluorescence and the surface area by BET (see Table 1).

TABLE 1

Characteristics of the catalysts studied

\begin{tabular}{l|l|c|c}
\hline \multicolumn{1}{c|}{ Support } & $\begin{array}{c}\text { Synthesis method } \\
(\% \mathrm{wt})\end{array}$ & $\begin{array}{c}\text { Co content } \\
\left(\mathrm{m}^{2} / \mathrm{g}\right)\end{array}$ & Surface area \\
\hline None & Commercial oxide & 73.4 & 10 \\
\hline $\mathrm{SiO}_{2}$ & Mechanical mixing & 17.0 & 380 \\
\hline $\mathrm{HZSM}-5$ & Mechanical mixing & 5.9 & 360 \\
\hline $\mathrm{Al}_{2} \mathrm{O}_{3}$ & Impregnation & 17.0 & 180 \\
\hline $\mathrm{TiO}_{2}$ & Impregnation & 12.0 & 20 \\
\hline $\mathrm{SiO}_{2}$ & Impregnation & 17.0 & 460 \\
\hline $\mathrm{SiO}_{2}$ (sol) & Sol-gel & 23.4 & 350 \\
\hline
\end{tabular}

An additional reference sample was produced by cation exchange of HZSM-5 zeolite in cobalt nitrate solution, resulting in a $2 \%$ loading of cobalt. This sample is refered to below as CoZSM-5.

\subsection{Catalyst Treatment}

To study the effect of impregnation with distilled water on the catalyst structure, different experimental procedures were compared.

\subsubsection{Wetting of Unreduced Samples Followed by Drying under Oxidising Atmosphere}

The initial calcined catalysts were impregnated with water to incipient wetness. Then they were dried at $393 \mathrm{~K}$ under air for $4 \mathrm{~h}$.

\subsubsection{Reduction, Passivation and Wetting Followed by Drying}

The initial calcined catalysts were reduced under hydrogen at $723 \mathrm{~K}$ for $1 \mathrm{~h}$. The temperature of the reduction of the $\mathrm{Co} / \mathrm{Al}_{2} \mathrm{O}_{3}$ sample was fixed at $823 \mathrm{~K}$ since this catalyst was found to be more difficult to reduce. After the reduction the catalysts were cooled to room temperature under hydrogen. Then, the hydrogen was replaced by nitrogen and the catalysts were passivated by allowing air to leak slowly into the reaction chamber. The passivated catalysts were impregnated with water to incipient wetness and dried under air at $393 \mathrm{~K}$ for $4 \mathrm{~h}$.

Some catalysts, reduced and passivated as described above, were impregnated with water and then dried under nitrogen at $393 \mathrm{~K}$ for $4 \mathrm{~h}$. This treatment allowed the effect of an oxidising atmosphere during drying to be estimated. 


\subsubsection{Reduction and Passivation Followed by Drying}

To separate the effect of aqueous impregnation from any effect coming from reduction and drying, the initial catalysts were reduced and passivated as described above and then dried under air at $393 \mathrm{~K}$.

\subsection{Catalyst Characterisation}

XRD measurements were carried out using $\mathrm{Cu}(\mathrm{K} \alpha)$ radiation on a Siemens diffractometer at room temperature. The presence of different phases $\left(\mathrm{CoO}, \mathrm{Co}_{3} \mathrm{O}_{4}, \mathrm{Co}\right.$ metal $)$ was found in the samples produced by reduction, wetting and drying at $393 \mathrm{~K}$. The corresponding XRD peaks were rather broad and overlapped. This made quantification of $\mathrm{Co}$ distribution between different phases rather difficult. In order to quantify information from XRD patterns more accurately the samples were calcined under air at $873 \mathrm{~K}$ before XRD examination. $\mathrm{Co}_{3} \mathrm{O}_{4}$ was the only crystalline cobalt containing phase detected in the catalysts after this reoxidation. The powdered samples $(0.2 \mathrm{~g}$ each $)$ were placed on a clean ceramic slide and pressed by hand. $\mathrm{Co}_{3} \mathrm{O}_{4}$ particle size was determined using the Scherrer formula relating line width to crystallite dimensions. The fraction of crystalline $\mathrm{Co}_{3} \mathrm{O}_{4}$ was measured by determining the ratio of intensities of the main $\mathrm{Co}_{3} \mathrm{O}_{4}$ diffraction peaks in the samples to those obtained from calibration mixtures of $\mathrm{Co}_{3} \mathrm{O}_{4}$ and the appropriate support.

FTIR spectra were measured using a Digilab FTS 80 spectrophotometer in a quartz cell with $\mathrm{KBr}$ windows which allows the samples to be treated under vacuum or under various gases at high temperatures. Before carbon monoxide adsorption the samples $(\sim 16-17 \mathrm{mg})$ were heated overnight at $493 \mathrm{~K}$ under vacuum. They were then exposed to hydrogen ( $p=250 \mathrm{mbar})$ and treated under hydrogen at $553 \mathrm{~K}$ and $623 \mathrm{~K}$ for $10 \mathrm{~min}$ and at $723 \mathrm{~K}$ for $40 \mathrm{~min}$. The $\mathrm{Co} / \mathrm{Al}_{2} \mathrm{O}_{3}$ was additionally heated under hydrogen at $823 \mathrm{~K}$ for $40 \mathrm{~min}$ to assure reduction of the cobalt. The rate of temperature increase was $5 \mathrm{~K} / \mathrm{min}$. After desorption of hydrogen under vacuum $\left(<10^{-5} \mathrm{mbar}\right)$ at room temperature carbon monoxide was adsorbed on the reduced catalysts at room temperature ( $p_{\mathrm{CO}}=35$ mbar).

X-ray photoelectron spectroscopy (XPS) was carried out in a Kratos XSAM800 instrument using an Al source. Samples were prepared by pressing the catalyst onto indium metal supports. Quantification of the atomic $\mathrm{Co} / \mathrm{Si}$ ratios, obtained by correcting peak areas for the instrument sensitivity factors, was verified using a cobalt silicate reference.

EXAFS experiments were carried out in the Laboratoire pour l'utilisation de rayonnement électromagnétique (LURE, Orsay, France) at the EXAFS4 beam line using synchrotron radiation from the DCI storage ring running at $1.85 \mathrm{GeV}$ with an average current of $250 \mathrm{~mA}$. The EXAFS data were taken in the transmission mode through a double crystal Si (111) monochromator using two ion chambers as detectors. The EXAFS unit, identical to that designed by Lytle [8, 9], allows in situ treatment of samples at temperatures up to $773 \mathrm{~K}$. The sample was reduced in situ using a temperature program (298-723 K, $5 \mathrm{~K} / \mathrm{min}$ ) with a total reduction time of $85 \mathrm{~min}$. The time of measuring an X-ray absorption spectrum (7550$8400 \mathrm{eV}$ ) was about $40 \mathrm{~min}$.

The Co K-edge extended X-ray absorption fine structure region of the spectra for $\mathrm{Co} /$ silica catalysts was analysed using a standard data analysis procedure [10]. The EXAFS spectrum was first transformed from $k$ space $\left(k^{3}\right.$, Hanning windows $2.8,4.2,10.4,12 \AA^{-1}$ ) to $r$ space to obtain the radial distribution function (RDF). The EXAFS spectrum for one or several coordination shells was isolated by inverse Fourier transform of the RDF over the appropriate region and fitted using the single scattering EXAFS equation. The moduli of the Fourier transforms of EXAFS data and structural data for reference compounds $\mathrm{Co}$ foil, $\mathrm{Co}_{3} \mathrm{O}_{4}$ and $\mathrm{CoO}$ are shown in Figure 1 and in Table 2, respectively.

TABLE 2

Inter-atomic distances $(R)$ and coordination numbers $(N)$ for reference compounds

\begin{tabular}{l|c|c|l|l|l|l|l|l}
\hline & $R(\AA)$ & $N$ & & $R(\AA)$ & $N$ & & $R(\AA)$ & $N$ \\
\hline Co metal & & & CoO & & & Co3O & & \\
Co-Co & 2.51 & 12 & Co-O & 2.13 & 6 & Co-O & 1.89 & 4 \\
Co-Co & 3.57 & 6 & Co-Co & 3.02 & 12 & Co-O & 1.98 & 1.33 \\
Co-Co & 4.36 & 24 & Co-O & 3.69 & 8 & Co-Co & 2.85 & 4 \\
Co-Co & 5.02 & 12 & Co-Co & 4.27 & 6 & Co-Co & 3.35 & 8 \\
\hline
\end{tabular}

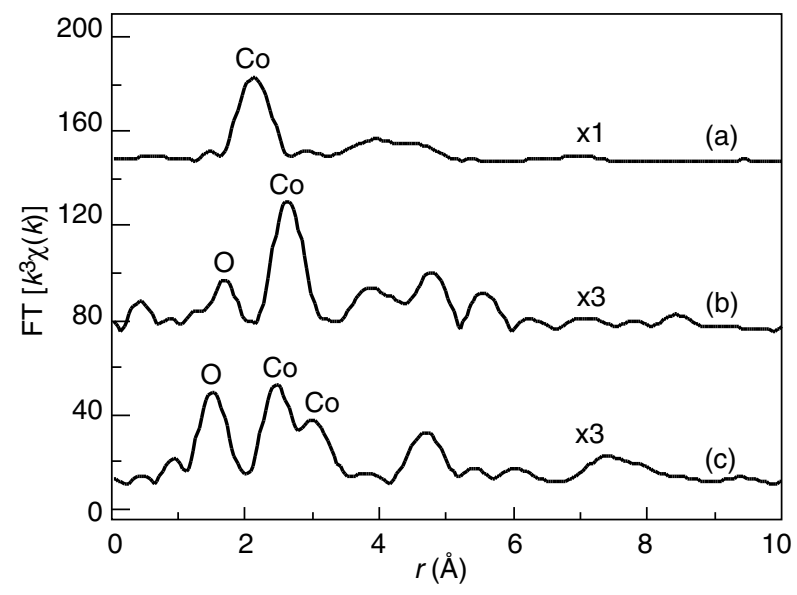

Figure 1

Fourier transform moduli of EXAFS data for (a) Co foil, (b) $\mathrm{CoO},(\mathrm{c}) \mathrm{Co}_{3} \mathrm{O}_{4}$. 
$\mathrm{Co}_{3} \mathrm{O}_{4}$ has a spinel type structure where $\mathrm{Co}^{2+}$ cations have a tetrahedral coordination and $\mathrm{Co}^{3+}$ are octahedrally coordinated with oxygen atoms. These two Co-O coordination shells are usually not separated in the Fourier transform moduli of $\mathrm{Co}_{3} \mathrm{O}_{4}$ and supported Co samples [12, 13]. For this reason, we fitted them with single shell parameters assuming that the shell contains disorder, i.e. a larger value of the Debye-Waller factor as compared with that for a single shell.

As can be seen from the Figure 1, the peaks in the Fourier transform attributed to Co-Co second and third coordination shells are overlapped. Thus, the inverse Fourier transform in the region of 2.02-3.57 $\AA$ was fitted using the parameters for two Co-Co coordination shells at $\mathrm{R} \approx 2.85 \AA$ and $\mathrm{R} \approx 3.35 \AA$.

The phases and amplitudes for $\mathrm{Co}-\mathrm{O}$ and $\mathrm{Co}-\mathrm{Co}$ neighbours were calculated ab initio using the FEFF5 code [14].

Three polymorphs of $\mathrm{Co}_{2} \mathrm{SiO}_{4}$ are known [11] all characterised by distorted cobalt environments. The $\alpha$ form has the olivine structure type with average coordinations for the first three shells of $6 \mathrm{Co}-\mathrm{O}$ ( 2.07 to $2.23 \AA$ ), $4.5 \mathrm{Co}-\mathrm{Si}$ (2.72 to $2.8 \AA$ ), and 3 Co-Co (3.0 to $3.22 \AA$ ). The $\beta$ and $\gamma$ forms are based on the spinel structure with average coordinations for the first three shells of $6 \mathrm{Co}-\mathrm{O}$ (2.05 to $2.15 \AA$ ), $6.5 \mathrm{Co}-\mathrm{Co}$ (2.88 to $3.09 \AA$ ), and $6 \mathrm{Co}-\mathrm{Si}$ (3.32 to $3.38 \AA$ ). The moduli of the Fourier transforms of EXAFS data for $\alpha$ and $\beta$ forms are shown in Figure 2 where it can be seen that for the $\beta$ form the distant silicon atoms in the third shell do not contribute strongly to the signal.

TPR profiles are obtained by passing a mixture of hydrogen and inert gas over the metal oxide while increasing the temperature at a linear programmed rate. Peak positions in TPR spectra are determined by the chemical nature and the environment of the reducible species.

TPR experiments were performed in a tubular quartz reactor. The gas flow $\left(5 \% \mathrm{H}_{2} / \mathrm{Ar}\right)$ was fixed at $30 \mathrm{ml} / \mathrm{min}$. The TPR investigations were performed on catalysts calcined prior to analysis $(2 \mathrm{~h}$ at $673 \mathrm{~K}$ ). The temperature was raised at a constant rate of $2 \mathrm{~K} / \mathrm{min}$ from 298 to $1223 \mathrm{~K}$. The samples were then maintained at $1223 \mathrm{~K}$ during $2 \mathrm{~h}$ and afterwards cooled to room temperature.

\section{RESULTS}

\subsection{Starting Materials}

For the bulk commercial cobalt oxide and for silica supported samples (Fig. 3) $\mathrm{Co}_{3} \mathrm{O}_{4}$ was the only crystalline phase detected by XRD. XRD peaks assigned to the zeolite and $\mathrm{Co}_{3} \mathrm{O}_{4}$ phases were observed in the XRD pattern of the $\mathrm{Co}_{3} \mathrm{O}_{4} / \mathrm{HZSM}-5$ mechanical mixture. XRD patterns of the initial $\mathrm{Co} /$ alumina sample showed lines attributed to the crystalline phases $\mathrm{Co}_{3} \mathrm{O}_{4}$ and $\gamma \mathrm{Al}_{2} \mathrm{O}_{3}$ (see Fig. 3).

In the XRD patterns of the $\mathrm{Co} / \mathrm{TiO}_{2}$ sample lines attributed to the rutile and anatase phases as well as to crystalline $\mathrm{Co}_{3} \mathrm{O}_{4}$ were observed. Analysis of the intensities of XRD patterns shows that the support consists of $80 \%$ rutile and $20 \%$ anatase with crystallites larger than $1000 \AA$ for both phases.

The percentage of $\mathrm{Co}$ in the crystalline $\mathrm{Co}_{3} \mathrm{O}_{4}$ phase and the diameter of the crystallite particles $\left(\mathrm{D} \mathrm{Co}_{3} \mathrm{O}_{4}\right)$ in the oxidised catalysts, measured using $\mathrm{XRD}$, are presented in

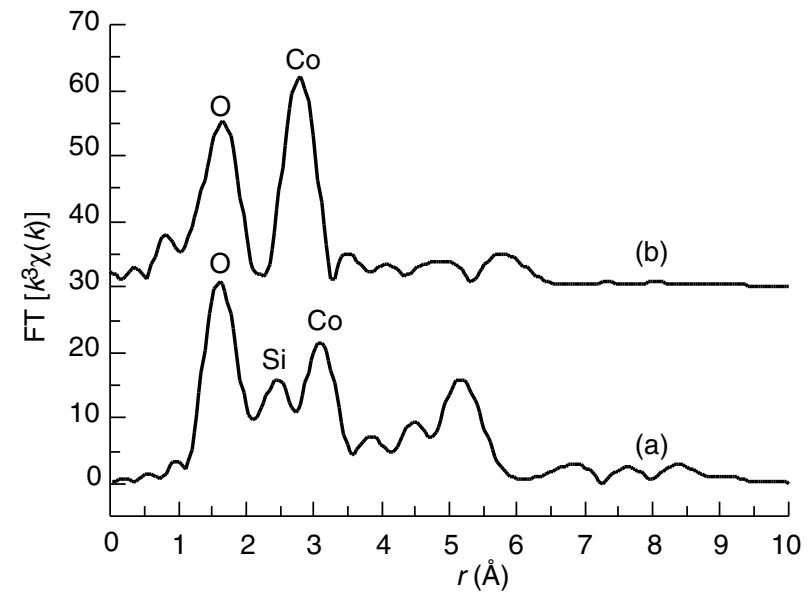

Figure 2

Fourier transform moduli of EXAFS data for (a) $\alpha \mathrm{Co}_{2} \mathrm{SiO}_{4}$ and (b) $\beta \mathrm{Co}_{2} \mathrm{SiO}_{4}$

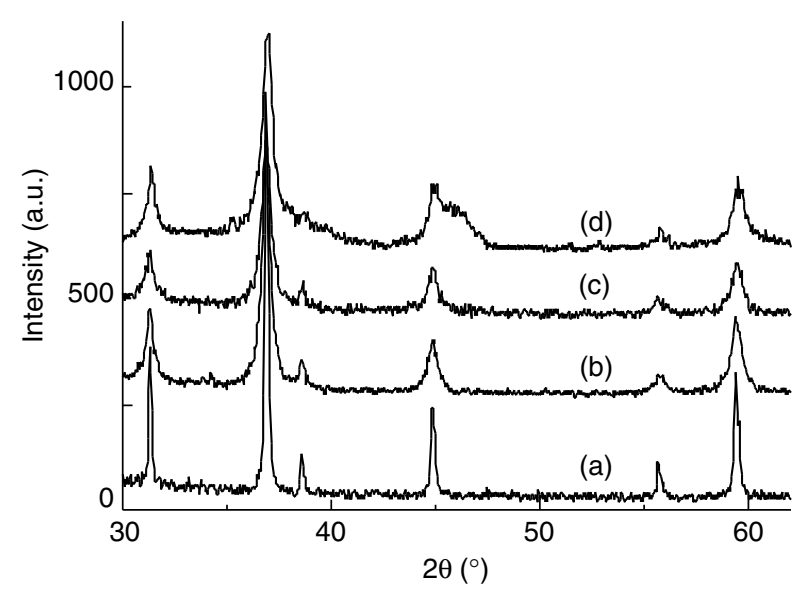

Figure 3

XRD patterns of (a) $\mathrm{Co}_{3} \mathrm{O}_{4}+\mathrm{SiO}_{2}$ mixture, (b) $\mathrm{Co} / \mathrm{SiO}_{2}$ (sol), (c) $\mathrm{Co} / \mathrm{SiO}_{2}$ prepared by impregnation, (d) $\mathrm{Co} / \mathrm{Al}_{2} \mathrm{O}_{3}$. 
Table 3. Virtually all of the cobalt is visible as $\mathrm{Co}_{3} \mathrm{O}_{4}$ for the mechanical mixtures and for $\mathrm{Al}_{2} \mathrm{O}_{3}$ and $\mathrm{TiO}_{2}$ supports. On silica, a significant fraction of the cobalt is not detectable by XRD. Particle diameters for supported $\mathrm{Co}_{3} \mathrm{O}_{4}$ are about $200 \AA$ except in the case of $\mathrm{TiO}_{2}$ where the low support surface area may be the cause of formation of larger particles.

TABLE 3

XRD characterisation of the starting materials

\begin{tabular}{l|l|l}
\hline Sample & $\% \mathrm{Co}_{3} \mathrm{O}_{4}( \pm 10 \%)$ & $\mathrm{D} \mathrm{Co}_{3} \mathrm{O}_{4}(\AA)$ \\
\hline Bulk $\mathrm{Co}_{3} \mathrm{O}_{4}$ & 100 & $>1500$ \\
\hline $\begin{array}{l}\text { Mechanical mixture } \\
\mathrm{Co}_{3} \mathrm{O}_{4}+\mathrm{SiO}_{2}\end{array}$ & 100 & $>1500$ \\
\hline $\begin{array}{l}\mathrm{Mechanical} \mathrm{mixture} \\
\mathrm{Co}_{3} \mathrm{O}_{4}+\mathrm{HZSM}-5\end{array}$ & 100 & $>1500$ \\
\hline $\mathrm{Co} / \mathrm{Al}_{2} \mathrm{O}_{3}$ & 98 & $170( \pm 20)$ \\
\hline $\mathrm{Co} / \mathrm{TiO}_{2}$ & 96 & $700( \pm 20)$ \\
\hline $\mathrm{Co} / \mathrm{SiO}_{2}$ & 86 & $200( \pm 20)$ \\
\hline $\mathrm{Co} / \mathrm{SiO}_{2}(\mathrm{sol})$ & 73 & $200( \pm 20)$ \\
\hline
\end{tabular}

FTIR spectra of adsorbed carbon monoxide showed no sites associated with Co species in the initial reduced samples of bulk $\mathrm{Co}_{3} \mathrm{O}_{4}$ and the mechanical mixtures. This was probably due to very large sizes of Co particles and the consequent low concentration of the surface metal sites.

Three main FTIR bands due to adsorbed CO were observed in the spectra of the initial zeolite and in the $\mathrm{Co}_{3} \mathrm{O}_{4} / \mathrm{HZSM}-5$ mechanical mixture (see Fig. 6a below). A band at $2170 \mathrm{~cm}^{-1}$ is attributed to the complexes of carbon monoxide with the bridged hydroxyl groups of the zeolite. Bands at $2193 \mathrm{~cm}^{-1}$ and $2220 \mathrm{~cm}^{-1}$ have been attributed [15, $16]$ to the complexes of carbon monoxide with the Lewis sites and possibly with sites related to extra framework $\mathrm{Al}^{3+}$ species in the HZSM-5 zeolite. Evacuation of carbon monoxide at room temperature was found to result in practically complete removal of all FTIR bands of adsorbed carbon monoxide for the zeolite.

Several bands were observed in the FTIR spectra of CO adsorbed on reduced samples of the other starting materials (see Fig. 4).

From the literature $[13,17-21]$, the band at $2027 \mathrm{~cm}^{-1}$ is attributed to carbon monoxide adsorbed on Co metal sites. The band at $2143 \mathrm{~cm}^{-1}$ seems to be attributable to $\mathrm{Co}^{2+}$ ions located in the $\mathrm{CoO}$ phase, an intermediate species during the reduction of $\mathrm{Co}_{3} \mathrm{O}_{4}$ to Co metal. The FTIR band at $2180 \mathrm{~cm}^{-1}$ has been attributed $[13,17,22]$ to the complexes of carbon monoxide with low coordination $\mathrm{Co}^{n+}$ ions $(n=2$ or 3 ). These species are not reduced by the treatment applied before $\mathrm{CO}$ adsorption. The band at $2180 \mathrm{~cm}^{-1}$ is particularly intense

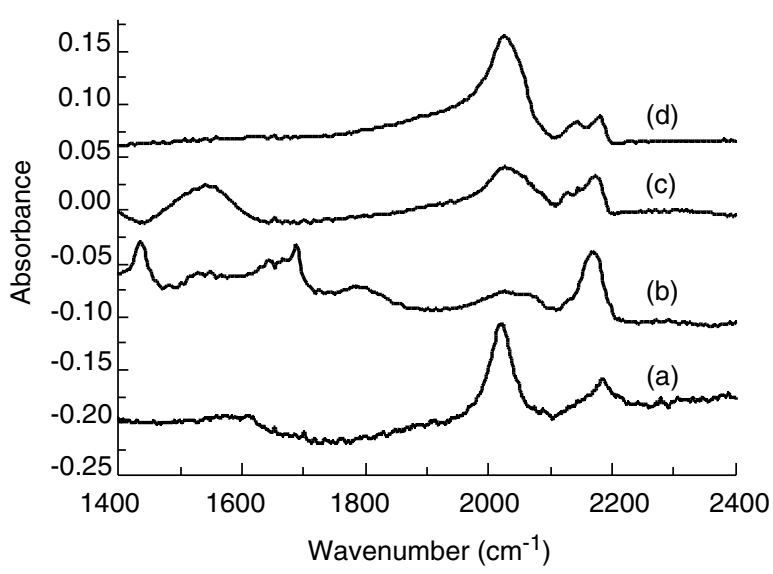

Figure 4

FTIR spectra of $\mathrm{CO}$ adsorbed on (a) $\mathrm{Co} / \mathrm{TiO}_{2}$, (b) $\mathrm{Co} / \mathrm{Al}_{2} \mathrm{O}_{3}$, (c) $\mathrm{Co} / \mathrm{SiO}_{2}$ (sol), (d) $\mathrm{Co} / \mathrm{SiO}_{2}$ prepared by impregnation.

for the alumina support, despite the high reduction temperature for this sample.

Various formate and hydrogen-carbonate structures characterised [23] by bands in the region $1400-1800 \mathrm{~cm}^{-1}$ are also seen in the FTIR spectra, in particular for carbon monoxide adsorption on alumina.

\subsection{Effect of Wetting Followed by Drying}

Whatever the support, wetting of the calcined samples followed by drying in air did not result in any changes in the concentration of $\mathrm{Co}_{3} \mathrm{O}_{4}$ crystalline phase measured by XRD and did not modify the surface sites which were followed using FTIR with carbon monoxide as a molecular probe.

\subsection{Effect of Reduction and Wetting Followed by Drying}

Reduction and wetting followed by drying did not result in any measurable decrease in the intensity or broadening of the XRD peaks of the bulk oxide. Calculation using the Scherrer equation showed that the average diameter of $\mathrm{Co}_{3} \mathrm{O}_{4}$ crystallites was larger than $1500 \AA$ both in the initial and treated samples.

The large diameter of $\mathrm{Co}_{3} \mathrm{O}_{4}$ particles and the consequent small surface area of bulk oxide are probably the reason why we did not see any FTIR bands arising from carbon monoxide adsorption on this sample. These results suggest that impregnation of the reduced and passivated oxide, followed by drying at $393 \mathrm{~K}$ and reoxidation did not result in any major modification of the bulk $\mathrm{Co}_{3} \mathrm{O}_{4}$ crystalline particles. 
Impregnation of the reduced and passivated mechanical mixtures of $\mathrm{Co}_{3} \mathrm{O}_{4}$ and $\mathrm{SiO}_{2}$ or HZSM-5 followed by drying and calcination caused a significant increase in the width of the XRD peaks and a slight decrease in the concentration of $\mathrm{Co}_{3} \mathrm{O}_{4}$ crystalline phase. The FTIR spectra of the treated solids showed the appearance of new FTIR bands. For the $\mathrm{Co}_{3} \mathrm{O}_{4} / \mathrm{SiO}_{2}$ mechanical mixture the appearance of a band at $2181 \mathrm{~cm}^{-1}$ (Fig. 5) shows the creation of low coordination $\mathrm{Co}^{n+}$ ions $(n=2$ or 3$)$.

The FTIR spectrum of the $\mathrm{Co}_{3} \mathrm{O}_{4} / \mathrm{HZSM}-5$ sample also shows a new band, at $2206 \mathrm{~cm}^{-1}$. As demonstrated in Figure 6, this band is also seen in the spectrum of carbon monoxide adsorbed on CoZSM- 5 zeolite prepared using ion exchange where it is assigned to the complexes of carbon monoxide with cobalt ions located in the cationic sites of the zeolite.

Thus, impregnation of the reduced and passivated mechanical mixtures results in diffusion of cations, initially located in the $\mathrm{Co}_{3} \mathrm{O}_{4}$ crystallites, to sites on $\mathrm{SiO}_{2}$ or inside the zeolite framework. Our experiments also showed that Co cations located in the cationic sites of HZSM-5 zeolite could not be reduced by hydrogen at temperatures up to $823 \mathrm{~K}$.

XRD data for all solids are presented in Table 4. Impregnation of the reduced and passivated catalysts resulted in a decrease in the concentration of $\mathrm{Co}_{3} \mathrm{O}_{4}$ crystalline phase accompanied by broadening of the XRD lines indicating a reduction of particle size. This is demonstrated by the XRD patterns of the $\mathrm{Co} / \mathrm{SiO}_{2}$ sample in Figure 7, (a) and (b). The loss of crystalline $\mathrm{Co}_{3} \mathrm{O}_{4}$ was limited on the alumina support, where the main effect was a reduction in particle size, but was pronounced for $\mathrm{SiO}_{2}$. Wetting and calcining of the solgel catalyst after reduction leads to a smaller decrease in the concentration of $\mathrm{Co}_{3} \mathrm{O}_{4}$ crystalline phase compared to the samples prepared using impregnation. The $\mathrm{TiO}_{2}$ support showed an effect intermediate between $\mathrm{Al}_{2} \mathrm{O}_{3}$ and $\mathrm{SiO}_{2}$.

TABLE 4

Effect of reduction, wetting and recalcination on the crystalline phases

\begin{tabular}{|c|c|c|c|c|}
\hline \multirow[t]{2}{*}{ Sample } & \multicolumn{2}{|c|}{ Initial } & \multicolumn{2}{|c|}{$\begin{array}{l}\text { Reduction, wetting } \\
\text { and recalcination }\end{array}$} \\
\hline & $\begin{array}{c}\% \mathrm{Co}_{3} \mathrm{O}_{4} \\
\pm 10 \%\end{array}$ & $\begin{array}{c}\mathrm{D} \mathrm{Co}_{3} \mathrm{O}_{4} \\
(\AA)\end{array}$ & $\begin{array}{c}\% \mathrm{Co}_{3} \mathrm{O}_{4} \\
\pm 10 \%\end{array}$ & $\begin{array}{c}\mathrm{D} \mathrm{Co}_{3} \mathrm{O}_{4} \\
(\AA)\end{array}$ \\
\hline Bulk $\mathrm{Co}_{3} \mathrm{O}_{4}$ & 100 & $>1500$ & 100 & $>1500$ \\
\hline $\begin{array}{l}\text { Mechanical mixture } \\
\mathrm{Co}_{3} \mathrm{O}_{4}+\mathrm{SiO}_{2}\end{array}$ & 100 & $>1500$ & 84 & $600 \pm 100$ \\
\hline $\begin{array}{l}\text { Mechanical mixture } \\
\mathrm{Co}_{3} \mathrm{O}_{4}+\mathrm{HZSM}-5\end{array}$ & 100 & $>1500$ & 89 & $550 \pm 100$ \\
\hline $\mathrm{Co} / \mathrm{Al}_{2} \mathrm{O}_{3}$ & 98 & $170 \pm 20$ & 83 & $80 \pm 10$ \\
\hline $\mathrm{Co} / \mathrm{TiO}_{2}$ & 96 & $680 \pm 100$ & 67 & $150 \pm 20$ \\
\hline $\mathrm{Co} / \mathrm{SiO}_{2}$ & 86 & $200 \pm 20$ & 34 & $60 \pm 10$ \\
\hline $\mathrm{Co} / \mathrm{SiO}_{2}(\mathrm{sol})$ & 73 & $200 \pm 20$ & 52 & $120 \pm 10$ \\
\hline
\end{tabular}

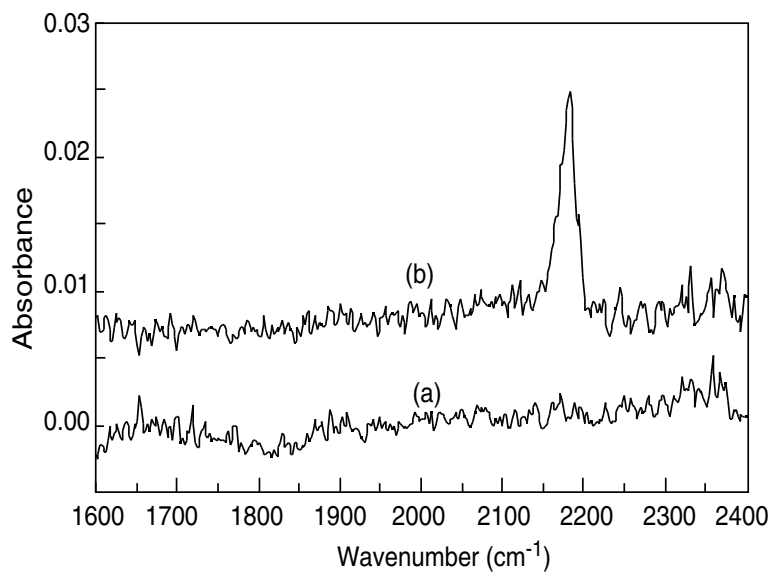

Figure 5

FTIR spectra of $\mathrm{CO}$ adsorbed on the mechanical mixture of $\mathrm{Co}_{3} \mathrm{O}_{4}$ and $\mathrm{SiO}_{2}$ (a), before and (b), after reduction, passivation, wetting and drying.

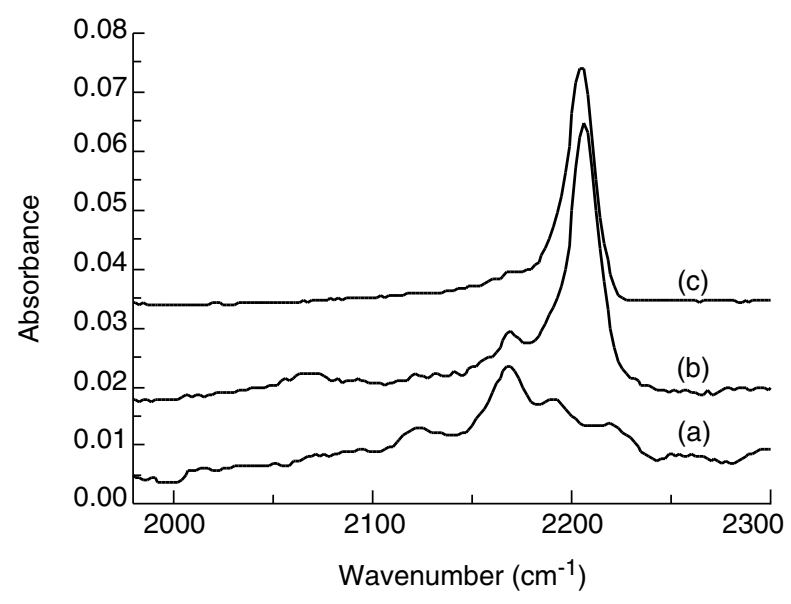

Figure 6

FTIR spectra of $\mathrm{CO}$ adsorbed on the mechanical mixture of $\mathrm{Co}_{3} \mathrm{O}_{4}$ and HZSM-5 zeolite (a), before and (b), after reduction, passivation wetting and recalcination compared with (c), the cation exchanged sample CoZSM-5.

Comparison of the results obtained for the impregnated samples dried under air and under nitrogen demonstrates that the decrease in the concentration of $\mathrm{Co}_{3} \mathrm{O}_{4}$ crystallites was slightly more pronounced when the catalyst was dried under air (Fig. 7 (b)) than under inert atmosphere (Fig. 7 (c)).

The treatment resulted in the appearance for the $\mathrm{Co} / \mathrm{Al}_{2} \mathrm{O}_{3}$ sample of a band at $2065 \mathrm{~cm}^{-1}$ in the FTIR spectrum of adsorbed CO (Fig. 8). In agreement with recent studies of carbon monoxide adsorbed on cobalt single-crystals [24, 25] 
the band could be due to cobalt metal atoms with low coordination (i.e. at defect sites or in small particles).

The FTIR spectrum of the $\mathrm{Co} / \mathrm{TiO}_{2}$ sample (Fig. 9) shows a decrease in the band at $2021 \mathrm{~cm}^{-1}$ relative to that at $2183 \mathrm{~cm}^{-1}$. Wetting and drying of the passivated sample results in this case in a decrease in the surface concentration of metal species relative to $\mathrm{Co}^{n+}$ ions.

The FTIR spectrum for the $\mathrm{Co} / \mathrm{SiO}_{2}$ catalyst (Fig. 10) shows a strong increase in the band due to unreduced $\mathrm{Co}^{n+}$ ions at $2181 \mathrm{~cm}^{-1}$. The band at $2027 \mathrm{~cm}^{-1}$ decreases in intensity and a new band appears at $2061 \mathrm{~cm}^{-1}$ attributed, as in the case of alumina, to the complexes of carbon monoxide with metal species in defect sites or on the surface of small particles [24, 25].

XPS analysis of the $\mathrm{Co} / \mathrm{SiO}_{2}$ catalyst prepared by impregnation showed that the surface $\mathrm{Co} / \mathrm{Si}$ ratio increased from 0.003 in the initial catalyst to 0.15 after wetting and drying of the reduced and passivated sample. The low $\mathrm{Co} / \mathrm{Si}$ ratio on the starting material is expected for this type of solid, containing large cobalt oxide crystallites on a high specific area support. The dramatic increase in the $\mathrm{Co} / \mathrm{Si}$ ratio after wetting indicates that the cobalt is strongly redispersed over the surface.

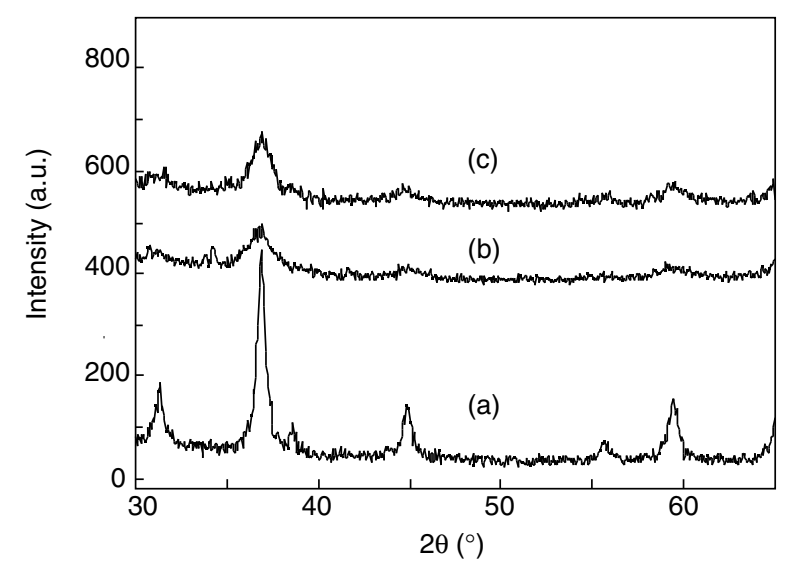

Figure 7

XRD patterns of the $\mathrm{Co} / \mathrm{SiO}_{2}$ sample as prepared (a), and after reduction, passivation, wetting and recalcination in air (b), or in dry nitrogen (c).

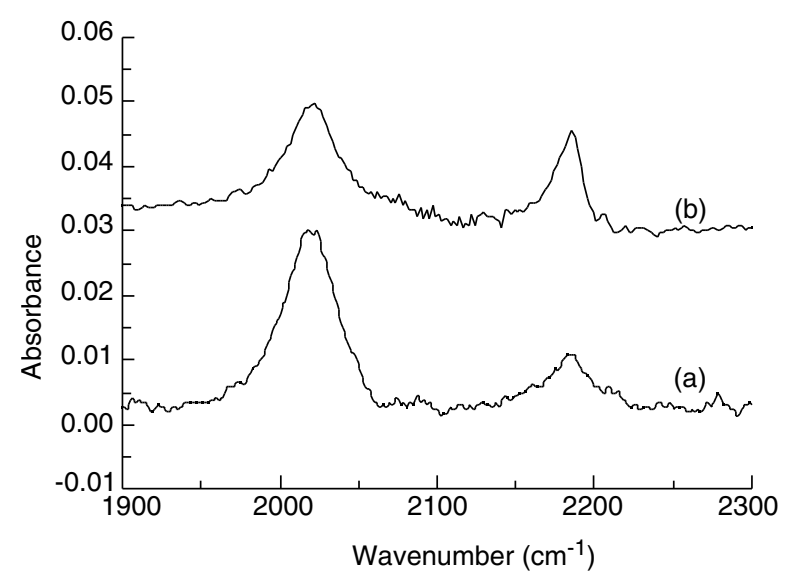

Figure 9

FTIR spectra of $\mathrm{CO}$ adsorbed on $\mathrm{Co} / \mathrm{TiO}_{2}(\mathrm{a})$, before and (b), after reduction, passivation wetting and drying.

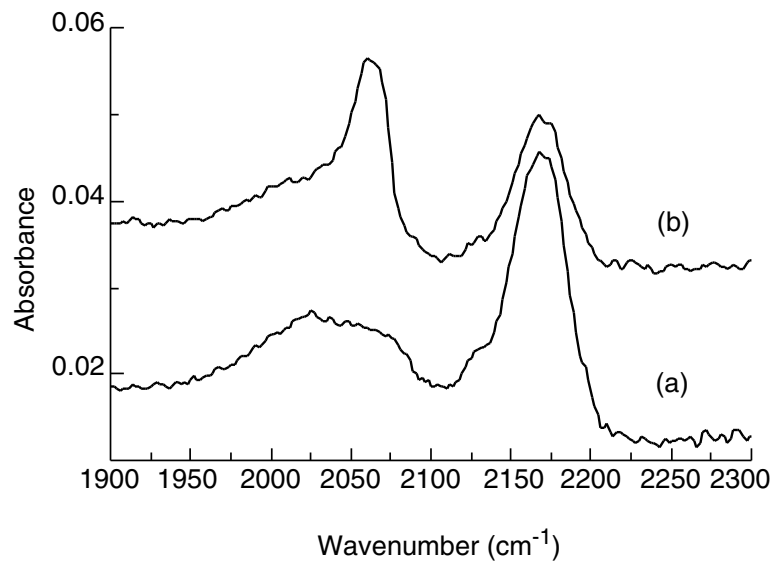

Figure 8

FTIR spectra of $\mathrm{CO}$ adsorbed on $\mathrm{Co} / \mathrm{Al}_{2} \mathrm{O}_{3}$ (a), before and (b), after reduction, passivation, wetting and drying.

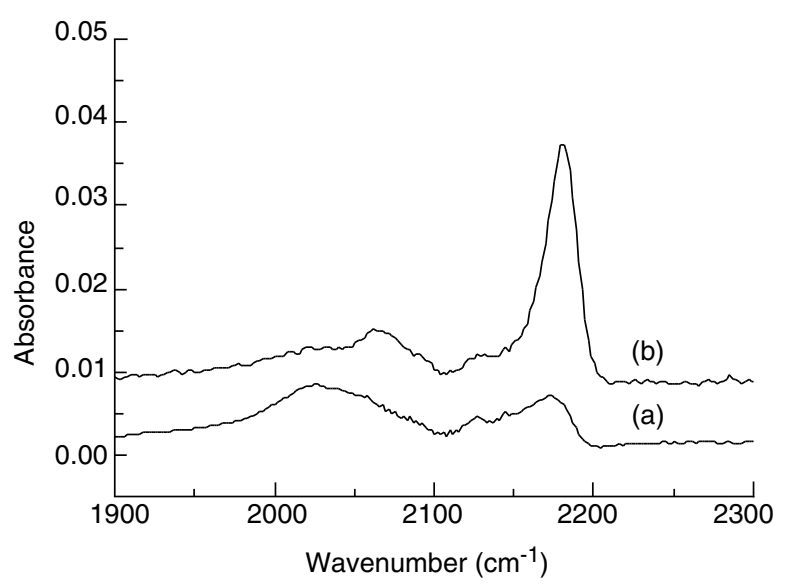

Figure 10

FTIR spectra of $\mathrm{CO}$ adsorbed on $\mathrm{Co} / \mathrm{SiO}_{2}$ (a), before and (b), after reduction, passivation, wetting and drying. 
Thus silica, the support showing the strongest loss of $\mathrm{Co}_{3} \mathrm{O}_{4}$ on reduction followed by wetting and recalcination, also shows the most clearly the creation of highly dispersed species that are not reduced by the pretreatment used for FTIR. For the alumina support both XRD and FTIR indicate the effect to be limited to particle break-up and an increase in reducible cobalt surface sites.

In order to gain further insight into the process, the different stages of reduction, passivation, wetting, drying at room temperature and recalcination were studied in situ by EXAFS for the $\mathrm{Co} / \mathrm{SiO}_{2}$ catalyst prepared by impregnation. The Fourier transform moduli of EXAFS at the different stages of the treatment are shown in Figure 11. Comparison of Figures 1 and 11 suggests that cobalt local coordination in the initial calcined sample is rather close to that in the bulk $\mathrm{Co}_{3} \mathrm{O}_{4}$ oxide. It is also clear that treatment of the catalysts under hydrogen at $723 \mathrm{~K}$ results in the reduction of Co. The Fourier transform modulus of EXAFS was very similar to that of bulk metal.

Exposure of the catalyst to air did not affect to any noticeable extent the local environment of Co atoms. This means that in the passivated sample, cobalt was still mainly

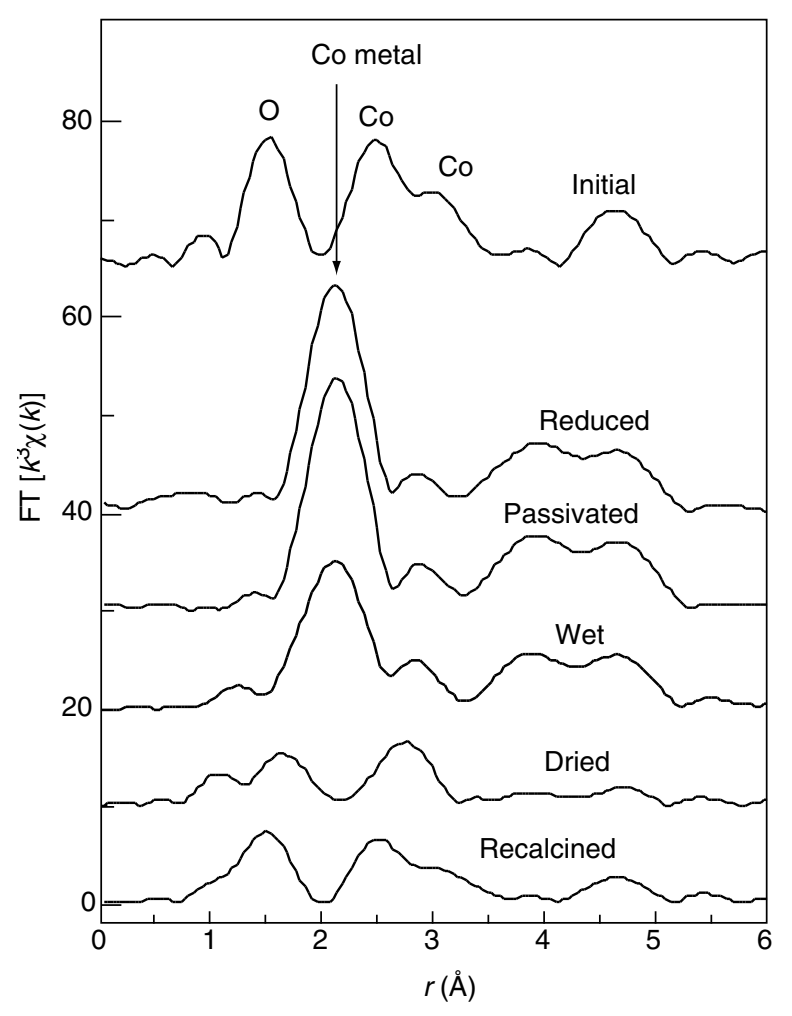

Figure 11

Fourier transforms of EXAFS data for $\mathrm{Co} / \mathrm{SiO}_{2}$ at various stages of treatment (chronologically from top). present as a metal. Treatment with water decreased the intensities of peaks in the Fourier transform modulus without changing the overall shape of the RDF. Again, no major change in the oxidation state of cobalt is detected.

Drying of the catalyst leads to a extensive oxidation of cobalt, shown by the reappearance of Co-O bonds. Finally, calcination of the dried catalysts results in a Fourier transform modulus very close to $\mathrm{Co}_{3} \mathrm{O}_{4}$. The peaks observed were however broader than in the bulk oxide, indicating larger disorder.

Whereas reduction followed by calcination has little effect on the quantitative EXAFS results (Table 5), wetting and calcination of reduced and passivated catalyst results in an increase in Debye-Waller factor which can be attributed to some disorder in local coordination of $\mathrm{Co}$ and, more importantly, in a decrease in Co-Co coordination numbers in the second and third Co coordination shells. The latter is due to a decrease in the average $\mathrm{Co}_{3} \mathrm{O}_{4}$ particle size.

Calcining in inert atmosphere in presence of water of the reduced and passivated catalyst results in an effect similar to calcination in air.

\section{TABLE 5}

coordination number, $N( \pm 1)$, inter-atomic distance, $R( \pm 0.03 \AA)$, and Debye-Waller factor, $\sigma( \pm 0.02 \AA)$, for bulk $\mathrm{Co}_{3} \mathrm{O}_{4}$ and for the $\mathrm{Co} / \mathrm{SiO}_{2}$ catalyst after various treatments

\begin{tabular}{|c|c|c|c|c|c|c|c|c|c|}
\hline & \multicolumn{3}{|c|}{$\begin{array}{l}\text { First shell } \\
\text { Co-O }\end{array}$} & \multicolumn{3}{|c|}{$\begin{array}{c}\text { Second shell } \\
\text { Co-Co }\end{array}$} & \multicolumn{3}{|c|}{$\begin{array}{c}\text { Third shell } \\
\text { Co-Co }\end{array}$} \\
\hline & $N$ & $\begin{array}{c}R \\
(\AA)\end{array}$ & $\begin{array}{c}\sigma \\
(\AA)\end{array}$ & $N$ & $\begin{array}{c}R \\
(\AA)\end{array}$ & $\begin{array}{c}\sigma \\
(\AA)\end{array}$ & $N$ & $\begin{array}{c}R \\
(\AA)\end{array}$ & $\begin{array}{c}\sigma \\
(\AA)\end{array}$ \\
\hline Bulk $\mathrm{Co}_{3} \mathrm{O}_{4}$ & 4 & 1.90 & 0.02 & 4 & 2.83 & 0.07 & 8 & 3.34 & 0.08 \\
\hline Initial catalyst & 4 & 1.91 & 0.02 & 4 & 2.82 & 0.07 & 9 & 3.33 & 0.09 \\
\hline $\begin{array}{l}\text { Reduced, } \\
\text { recalcined }\end{array}$ & 4.4 & 1.91 & 0.02 & 3.2 & 2.81 & 0.07 & 9.9 & 3.32 & 0.1 \\
\hline $\begin{array}{l}\text { Reduced, } \\
\text { impregnated, } \\
\text { recalcined } \\
\text { in air }\end{array}$ & 4.7 & 1.94 & 0.05 & 2.5 & 2.82 & 0.09 & 5.5 & 3.3 & 0.1 \\
\hline $\begin{array}{l}\text { Reduced, } \\
\text { impregnated, } \\
\text { recalcined } \\
\text { in } \mathrm{N}_{2}\end{array}$ & 4.8 & 1.93 & 0.06 & 2.8 & 2.82 & 0.09 & 5.3 & 3.35 & 0.11 \\
\hline
\end{tabular}

\subsection{Effect of Reduction Followed by Drying}

Reduction, passivation, drying and subsequent reoxidation resulted in a broadening of XRD peaks for all samples with the exception of bulk $\mathrm{Co}_{3} \mathrm{O}_{4}$ and the mechanical mixture $\mathrm{Co}_{3} \mathrm{O}_{4} / \mathrm{HZSM}-5$. The diameter of the $\mathrm{Co}_{3} \mathrm{O}_{4}$ particles, calculated using the Scherrer equation, are shown in Table 6. This treatment did not, however, affect the concentration of 
$\mathrm{Co}_{3} \mathrm{O}_{4}$ crystalline phase (integral intensity of the XRD peaks), again with the exception of $\mathrm{Co}_{3} \mathrm{O}_{4} / \mathrm{HZSM}-5$ mechanical mixture.

TABLE 6

Effect of reduction, passivation, drying and reoxidation on the crystalline phases

\begin{tabular}{|c|c|c|c|c|}
\hline \multirow[t]{2}{*}{ Sample } & \multicolumn{2}{|c|}{ Initial } & \multicolumn{2}{|c|}{$\begin{array}{l}\text { Reduced and } \\
\text { reoxidised }\end{array}$} \\
\hline & $\begin{array}{c}\% \mathrm{Co}_{3} \mathrm{O}_{4} \\
\pm 10 \%\end{array}$ & $\begin{array}{c}\mathrm{D} \mathrm{Co}_{3} \mathrm{O}_{4} \\
(\AA)\end{array}$ & $\begin{array}{c}\% \mathrm{Co}_{3} \mathrm{O}_{4} \\
\pm 10 \%\end{array}$ & $\begin{array}{c}\mathrm{D} \mathrm{Co}_{3} \mathrm{O}_{4} \\
(\AA)\end{array}$ \\
\hline Bulk $\mathrm{Co}_{3} \mathrm{O}_{4}$ & 100 & $>1500$ & 100 & $>1500$ \\
\hline $\begin{array}{l}\text { Mechanical mixture } \\
\mathrm{Co}_{3} \mathrm{O}_{4}+\mathrm{SiO}_{2}\end{array}$ & 100 & $>1500$ & 98 & $950 \pm 100$ \\
\hline $\begin{array}{l}\text { Mechanical mixture } \\
\mathrm{Co}_{3} \mathrm{O}_{4}+\mathrm{HZSM}-5\end{array}$ & 100 & $>1500$ & 82 & $>1500$ \\
\hline $\mathrm{Co} / \mathrm{Al}_{2} \mathrm{O}_{3}$ & 98 & $170 \pm 20$ & 95 & $85 \pm 10$ \\
\hline $\mathrm{Co} / \mathrm{TiO}_{2}$ & 96 & $680 \pm 100$ & 89 & $185 \pm 20$ \\
\hline $\mathrm{Co} / \mathrm{SiO}_{2}$ & 86 & $200 \pm 20$ & 85 & $100 \pm 10$ \\
\hline $\mathrm{Co} / \mathrm{SiO}_{2}(\mathrm{sol})$ & 73 & $200 \pm 20$ & 70 & $170 \pm 20$ \\
\hline
\end{tabular}

The reduction and drying treatment caused modifications in the relative intensities of bands in the FTIR spectra of adsorbed $\mathrm{CO}$ that suggest an increase in the available Co surface area. An example is shown in Figure 12 for the $\mathrm{Co} / \mathrm{Al}_{2} \mathrm{O}_{3}$ sample. The treatment leads to a higher intensity in the band at $2020 \mathrm{~cm}^{-1}$ attributed to interaction of $\mathrm{CO}$ with metallic cobalt surface sites.

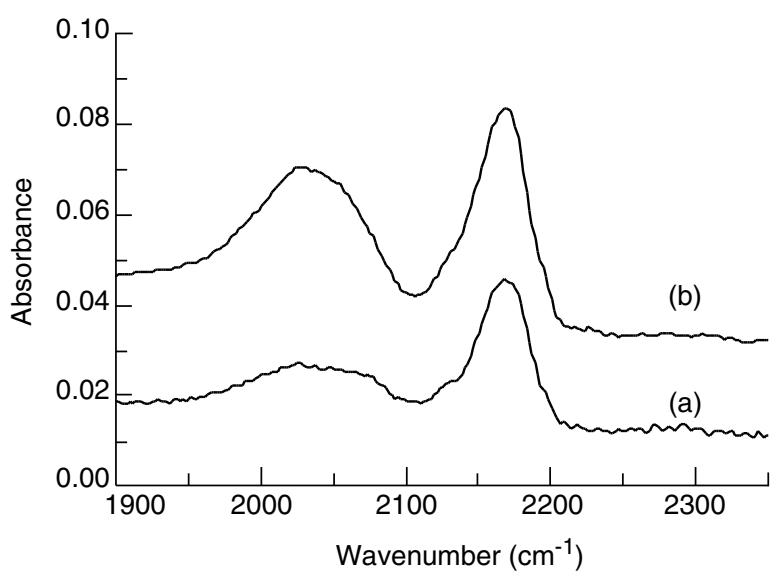

Figure 12

FTIR spectra of $\mathrm{CO}$ adsorbed on $\mathrm{Co} / \mathrm{Al}_{2} \mathrm{O}_{3}$ (a), before and (b), after reduction followed by drying.

\section{DISCUSSION}

Whilst wetting and drying of the initial calcined catalysts did not have any detectable effect on the structure of the catalysts, aqueous impregnation of the reduced and passivated catalysts leads to a decrease in both the concentration of $\mathrm{Co}_{3} \mathrm{O}_{4}$ crystalline phase and the average particle size. At the same time this treatment creates, or increases the concentration of $\mathrm{Co}^{n+}$ species that are not reduced by the pretreatment in FTIR. The large increase in the surface concentration of cobalt observed by XPS clearly indicates increased dispersion of cobalt.

These results suggest that the treatment leads to $\mathrm{Co}^{n+}$ species that are dispersed on the surface of the support in an XRD amorphous environment.

A decrease in particle size may be due to the reduction, passivation and drying involved in this process. This is shown by the systematic reduction in particle size for the catalysts that were reduced, passivated then dried and calcined. Average particle size is reduced by at least a factor of two for the catalysts prepared by cobalt nitrate impregnation. Reduction and drying alone did not however affect the concentration of $\mathrm{Co}_{3} \mathrm{O}_{4}$ crystalline phase except in the case of HZSM-5 zeolite. In the latter support, water trapped in the zeolite framework may be responsible for the redispersion of the cobalt.

Let us discuss the possible mechanism of transformation of cobalt crystalline phases on these catalysts. As seen from the Fourier transform moduli of EXAFS (Fig. 10), reduction of the $\mathrm{Co} / \mathrm{SiO}_{2}$ sample resulted, as expected, in the formation of metallic Co. Passivation of the catalysts followed by their short exposition to air or to water did not affect to any major extent the Fourier transform moduli. This indicates that passivation and wetting did not result in complete reoxidation of Co metal particles. The Co metal particles after passivation are however likely to be covered by a thin film of oxygen.

The most pronounced effect on the Co crystalline phases occurs during drying under air of wet catalysts. It can be suggested that drying under air in the presence of water results in the oxidation of Co metal and release of the $\mathrm{Co}^{n+}$ ions ( $n=2$ and/or 3 ) which can be hydrated by water and could diffuse to the surface of the support. The general outline of this process is presented in Figure 13. This idea is supported by the results of Haddad and Goodwin [6] who found that, for silica supported cobalt catalysts, the drying temperature of impregnated passivated catalysts had a significant effect on the concentration of Co crystalline phases. Our results also show that drying of the impregnated reduced and passivated catalysts under nitrogen had a similar but smaller effect on the concentration of $\mathrm{Co}_{3} \mathrm{O}_{4}$ crystalline phase. Drying of the catalysts in nitrogen would decrease the quantity of oxygen available for oxidation of Co metal species and would thus decrease the number of $\mathrm{Co}^{n+}$ hydrated ions released from the Co metal particles. 


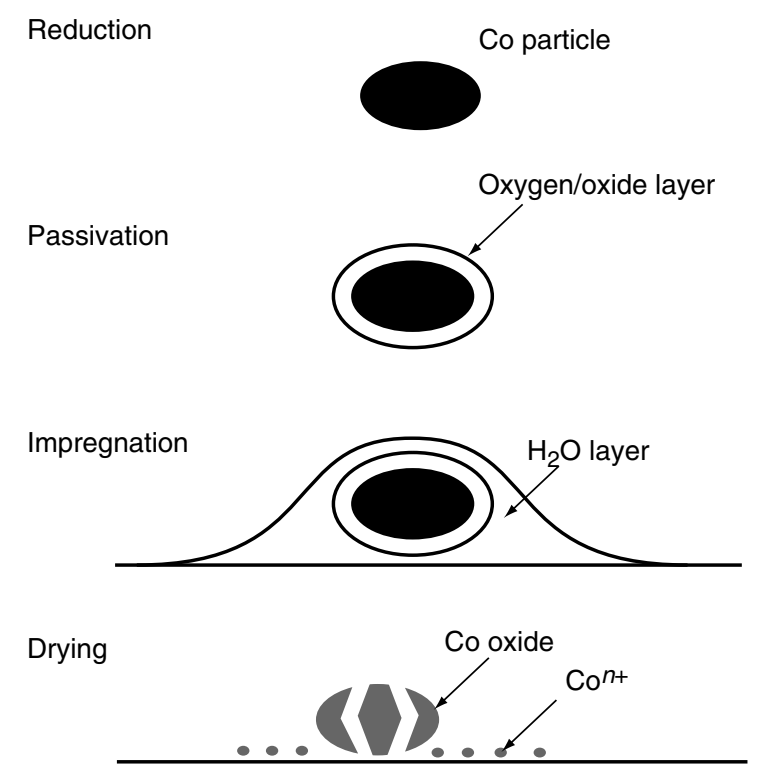

Figure 13

Schematic representation of cobalt redispersion.

Hydrothermal treatments similar to those occurring during the wetting-drying process are known to lead to a catalyst with lower reducibility. Kogelbauer et al. [26] suggested that this result is attributable to the formation of both reducible and non-reducible Co silicates. The formation of these compounds occurred only when metallic Co was present.

Comparison of the TPR profiles of the $\mathrm{Co} / \mathrm{SiO}_{2}$ catalyst before and after a treatment of reduction, passivation, wetting and drying in air (Fig. 14), provides useful information about the nature of cobalt species. The two reduction peaks observed for the initial catalyst can be attributed to the two step reduction of $\mathrm{Co}_{3} \mathrm{O}_{4}$ to $\mathrm{CoO}$ and the subsequent reduction $\mathrm{CoO}$ to $\mathrm{Co}$ metal $[20,27]$. Higher reduction temperatures can be taken as indicating greater interaction between cobalt species and the support. The shift of the reduction peak to higher temperatures for the treated $\mathrm{Co} / \mathrm{SiO}_{2}$ catalyst is thus coherent with a decrease in particle size. Consumption of hydrogen up to high temperatures indicates that some Co species formed after the wetting-recalcination treatment were not completely reducible, even up to $1173 \mathrm{~K}$.

Coulter and Sault [28] attributed the formation of an irreducible Co phase ( $\mathrm{T}>1123 \mathrm{~K}$ ) on $\mathrm{SiO}_{2}$ to the migration of $\mathrm{Co}^{2+}$ into the silica framework. It is also known that silica is mobile under hydrothermal conditions [29]. Either of these effects could lead to the encapsulation of part of the cobalt in the silica matrix, perhaps making it less accessible for hydrogen reduction during the TPR treatment. Kogelbauer et al. [26] proposed a similar explanation for broadening and the shift of the TPR peaks to higher temperature.

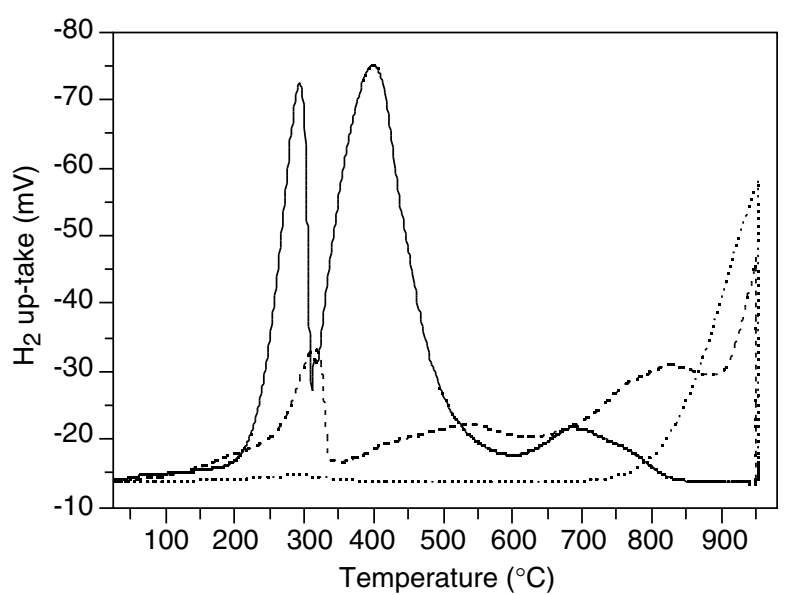

Figure 14

TPR profiles of $\mathrm{Co} / \mathrm{SiO}_{2}$ (full line : initial solid ; dashed line: after reduction, passivation, wetting and drying) and $\mathrm{Co}_{2} \mathrm{SiO}_{4}$ (dotted line).

The samples above were treated with water to incipient wetness. In order to explore further the dispersion of cobalt induced by drying in air, a sample of $\mathrm{Co} / \mathrm{SiO}_{2}$ prepared by impregnation was passivated then saturated by adding a large quantity of water. The solid resulting after drying was XRD amorphous and showed a single peak in TPR at high temperature $(>1123 \mathrm{~K})$.

EXAFS data for this solid (Fig. 15) clearly show the cobalt to have a local environment similar to $\beta \mathrm{Co}_{2} \mathrm{SiO}_{4}$. Quantitative analysis with two shells show the local cobalt environment to consist of six oxygen atoms at $2.04 \AA$ $(\sigma=0.08 \AA)$ and six cobalt atoms at $3.13 \AA(\sigma=0.08 \AA)$, close to the structure expected for the $\beta$ form. As noted above, Co-Si distances do not contribute significantly to the EXAFS signal in this structure. However, the EXAFS signature differs considerably from that of $\mathrm{Co}_{3} \mathrm{O}_{4}$.

Thus the ultimate state of dispersion of the cobalt appears to be an amorphous cobalt silicate close in structure to the spinel form. It should be noted that, in this structure, Co-OCo bonds are preserved. This is consistent with the idea that the formation of the amorphous silicate results from break-up of cobalt oxide particles.

The intensity of the effect of aqueous impregnation on the reduced and passivated catalysts varies between the different supports. The $\mathrm{Co} / \mathrm{SiO}_{2}$ catalyst prepared via impregnation and the $\mathrm{Co}_{3} \mathrm{O}_{4} / \mathrm{HZSM}-5$ mechanical mixture showed the greatest decrease in the intensity of XRD peaks attributed to $\mathrm{Co}_{3} \mathrm{O}_{4}$ crystalline phase. The effect was less pronounced in the catalyst prepared by the sol-gel technique. For $\mathrm{Co} / \mathrm{Al}_{2} \mathrm{O}_{3}$ and $\mathrm{Co} / \mathrm{TiO}_{2}$ samples the decrease in the concentration of $\mathrm{Co}_{3} \mathrm{O}_{4}$ is much smaller. Indeed, for alumina the FTIR spectra suggest the effect to be limited to the creation of smaller 


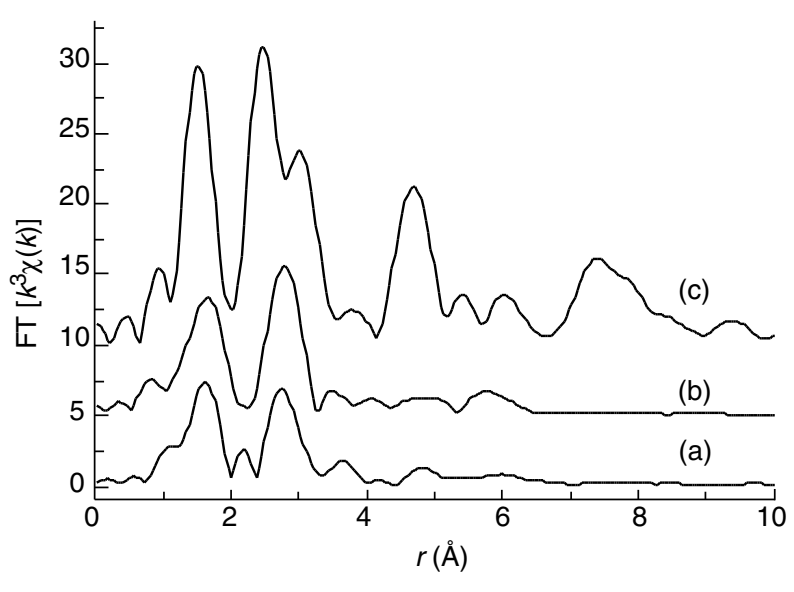

Figure 15

Modulii of the Fourier transforms of (a) the $\mathrm{Co} / \mathrm{SiO}_{2}$ sample reduced, passivated, saturated with water and dried, (b) $\beta \mathrm{Co}_{2} \mathrm{SiO}_{4}$, (c) $\mathrm{Co}_{3} \mathrm{O}_{4}$.

$\mathrm{Co}_{3} \mathrm{O}_{4}$ crystallites. The intensity of the observed effect is thus not directly related to the surface area of the support, nor to initial particle size.

The process suggested in Fig. 13 provides a framework to understand observed differences for different supports in the effect of wetting. It can be suggested that $\mathrm{Co}^{n+}$ ions, released during drying of reduced and passivated catalysts in contact with water, would react with the support to a different extent on silica, alumina, titanium oxide or zeolite. In the latter $\mathrm{Co}^{n+}$ ions released during impregnation and subsequent drying of passivated catalysts could react with the bridged hydroxyl groups inside the zeolite resulting in Co ions occupying the cation positions. In an analogous manner for the other supports, reactivity of the surface groups with $\mathrm{Co}^{n+}$ ions may be the main parameter determining the extent of redispersion. The results obtained by saturation of the $\mathrm{Co} / \mathrm{SiO}_{2}$ sample suggest that formation of a mixed oxide (silicate, aluminate or titanate) may be the driving force for the redispersion.

Smaller effects due to reduction, passivation and drying, both with and without wetting of the passivated sample, were observed for the $\mathrm{Co} / \mathrm{SiO}_{2}$ (sol) sample prepared by the sol-gel technique compared with the $\mathrm{Co} / \mathrm{SiO}_{2}$ sample prepared by impregnation. One would expect different textures of the sample in the two cases, indeed for the sol-gel technique the encapsulation of part of the cobalt by the support has been suggested [7]. This could lead to limitations both in particle break-up, due to constraints imposed by the surrounding support, and in contact between the cobalt particles and the wetting fluid.

\section{CONCLUSION}

Impregnation with distilled water of reduced and passivated cobalt catalysts, followed by drying, results in a significant modification of Co surface sites in supported catalysts. Cobalt particle break-up is induced by reduction, passivation and drying. A decrease in the concentration of Co crystalline phases, due to redispersion of cobalt on the support, is caused by migration of $\mathrm{Co}^{n+}$ ions in the presence of water. The effect is most pronounced on silica and HZSM-5 zeolite. A much smaller decrease in the concentration Co crystalline phases was observed on alumina and titania. It is suggested that differences in surface reactivity, as well as geometrical effects such as available surface area or encapsulation by the support, determine the extent of redispersion.

Redispersion of the cobalt leads to production of smaller particles and thus could be expected to increase cobalt dispersion. However, higher temperatures are required for reduction of the smaller particles produced [13]. Indeed part of the cobalt may remain in oxidised form even after high temperature treatment under hydrogen. Although one role of the promoter is to facilitate the reduction of cobalt, modifications due to the impregnation procedure may prevent achieving the desired result. The effects on the structure of Co species and their surface sites of secondary impregnation with water should therefore be taken into consideration when developing promoted Co containing catalysts. Effects on dispersion and catalytic performance attributed to the promoter element may be affected by redistribution of the cobalt during the impregnation. The study presented here has not been concerned with variation of the impregnation procedure to modify the extent of redispersion. The nature of the impregnation medium may be expected to influence the mobilisation of cobalt ions and thus induce greater or lesser redispersion. Further work using the characterisation techniques employed here should enable progress in optimisation of promoted cobalt catalysts.

\section{ACKNOWLEDGMENTS}

The authors acknowledge financial support of the European Union (contract No. JOF3-CT95-0016). The authors are also grateful to D. Bazin (LURE, Orsay) for assistance during EXAFS experiments and N. Zanier of IFP for assistance in FTIR spectroscopy measurements.

\section{REFERENCES}

1 Anderson, R.B. (1984) The Fischer-Tropsch Synthesis. Academic Press.

2 Bond, G.C. (1962) Catalysis by Metals, Academic Press, London New York.

3 Chaumette, P. (1996) Revue de l'Institut français du pétrole, Éditions Technip, Paris, 51, 711. 
4 Hindermann, J.P., Hutchings, G.J. and Kiennemann, A. (1993) Catal. Rev-Sci. Eng., 35, 1.

5 Iglesia, E., Soled, S.L. and Fiato, R.A. (1992) J. Catal., 137, 212.

6 Haddad, J. and Goodwin Jr., J.G. (1995) J. Catal., 157, 25.

7 Azib, H. (1996) Doctoral Thesis, Univ. P. et M. Curie.

8 Sinfelt, J.H., Via, G.H. and Lytle, F.M. (1984) Catal. Rev. Sci. Eng., 26, 81.

9 Short, D.R., Mansour, A.N., Cook, J.M., Sayers, D.E. and Katzer, J.R. (1983) J. Catal., 82, 299.

10 Michalowicz, A. (1990) Doctoral Thesis, Université Paris, Val-de-Marne.

11 Morimoto, N., Tokonami, M., Watanabe, M. and Koto, K. (1974) Amer. Mineral., 59, 475.

12 Huffmann, G.P., Shah, N., Zhao, J., Huggins, F.E., Hoost, T.E., Halvorsen, S. and Goodwin, J. (1995) J. Catal., 151, 17.

13 Khodakov, A., Lynch, J., Rebours, B., Bazin, D., Masson, B., Zanier, N. and Chaumette, P. (1997) J. Catal., 168, 16.

14 (a) Rehr, J.J., Zabinsky, S.I. and Albers, R.C. (1992) Phys. Rev. Let., 69, 39.

(b) Rehr, J.J. (1993) J. Appl. Phys., 32, 8.

(c) Rehr, J.J., Mustre de Leon, J., Zabinsky, S.I. and Albers, R.C. (1991) J. Am. Chem. Soc., 113, 5135.

(d) Mustre de Leon, J., Rehr, J.J., Zabinsky S.I. and Albers, R.C. (1991) Phys. Rev., 44, 4146.

15 Kustov, L.M., Kazansky, V.B., Beran, S., Kubelkova, L. and Jiru, P. (1987) J. Phys. Chem., 91, 5247.
16 Szanyi, J., Paffett, M.T. (1996) Microporous Materials, 7, 201.

17 Davydov (1991) IR Spectroscopy of Adsorbed Species on the Surface of Transition Metal Oxides, Willey \& Sons (Ed.) New York.

18 Heal, M.J., Leisegang, E.C. and Torrington, R.G. (1978) J. Catal., 51, 314.

19 Kazansky, V.B., Zaitsev, A.V., Borovkov, V.Yu. and Lapidus, A.L. (1988) Appl. Catal., 40, 17.

20 Lapidus, A., Krylova, A., Kazanskii, V., Borovkov, V., Zaitsev, A., Rathousky, J., Zukal, A. and Jancalkova, M. (1991) Appl. Catal., 73, 65.

21 Choi, J.G., Rhee, H.K. and Moon, S.H. (1985) Appl. Catal., 13, 269.

22 Canesan, P., Kuo, H.K., Saavedra, A. and De Angelis, R.J. (1978) J. Catal., 52, 310.

23 Padley, M.B., Rochester, C.H., Hutchings, G.J. and King, F. (1994) J. Catal., 148, 438.

24 Wilson, J. and de Groot, C. (1995) J. Phys. Chem., 99, 7860.

25 Beitel, G.A., Laskov, A., Oosterbeek, H. and Kuipers, E.W. (1996) J. Phys. Chem., 100, 12494.

26 Kogelbauer, A., Weber, J.C. and Goodwin, J.C. Jr (1995) Catal. Let., 34, 259.

27 Arnoldy, P. and Moulijn, J.A. (1985) J. Catal., 93, 38.

28 Coulter, K.E. and Sault, A.G. (1995) J. Catal., 154, 56.

29 Lund, C.R.F. and Dumesic, J.A. (1981) J. Catal., 72, 21.

Final manuscript received in May 1999 
